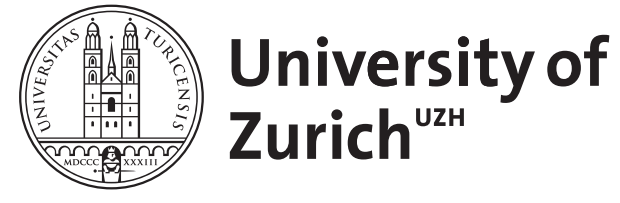

Zurich Open Repository and Archive

University of Zurich

University Library

Strickhofstrasse 39

CH-8057 Zurich

www.zora.uzh.ch

Year: 2013

\title{
Nonphysician-assisted suicide in Switzerland
}

Andorno, Roberto

DOI: https://doi.org/10.1017/S0963180113000054

Posted at the Zurich Open Repository and Archive, University of Zurich

ZORA URL: https://doi.org/10.5167/uzh-92579

Journal Article

Originally published at:

Andorno, Roberto (2013). Nonphysician-assisted suicide in Switzerland. Cambridge Quarterly of Healthcare Ethics, 22(3):246-253.

DOI: https://doi.org/10.1017/S0963180113000054 


\title{
Nonphysician-Assisted Suicide in Switzerland
}

\author{
ROBERTO ANDORNO
}

\section{An Unintended Permissive Policy on Assisted Suicide}

In general, legal responses to end-of-life issues are not very different in Switzerland than in most European countries. For instance, active euthanasia (i.e. killing on request) is illegal, although it is treated as a lesser offense than murder or manslaughter. Article 114 of the Swiss Penal Code reads, "Every person who, for honorable reasons, especially mercy, kills another person on his or her serious and pressing request shall be punished by imprisonment for a maximal term of three years or with a fine." Also, like in most European countries, the administration of medication (for instance, morphine) to relieve serious pain of a terminal patient, even though it may lead to the unintended consequence of hastening his or her death, is accepted, in both moral and legal terms. Similarly, like in many other countries, the withdrawal or withholding of life-sustaining treatments, even if not covered by any specific legal provision, is not treated as a criminal offense provided that certain conditions are fulfilled. ${ }^{1}$

The peculiarity of Switzerland regarding end-of-life issues only relates to assisted suicide. This practice, which is permitted, has two significant differences if compared to the situation in the other (few) European countries that allow it:
1) Nonphysician assisted suicide is permitted. Whereas in the Netherlands and Belgium only physicians are allowed to assist in a suicide, in Switzerland this assistance is provided by (nonphysicians) volunteers working for nonprofit organizations. The role of doctors is limited to prescribing the lethal drug and assessing the patient's decisional capacity; they do not perform the assistance in the suicide themselves. ${ }^{2}$ In this regard, the practice of assisted suicide in Switzerland is similar to the one in the US state Oregon. ${ }^{3}$

2) One need not have a particular medical condition (such as a terminal illness or an unbearable suffering) to request assistance with suicide. The only requirement is that the individual must have decisional capacity, because in the absence of it his or her act cannot be considered a "suicide" in legal terms. In fact, at present, according to a recent study, around $25 \%$ of people who die by assisted suicide in Switzerland do not have any serious or terminal illness, but are just old, or are simply "tired of life". ${ }^{4}$

The peculiarity of the Swiss situation is due to the circumstance that, unlike other countries allowing assisted suicide, Switzerland does not have any specific 
legal norms regulating this practice. This current situation has developed, not as the result of an explicit liberal policy, but rather at the initiative of nongovernmental right-to-die organizations, which took advantage of a gap in the legal system. The draft Penal Code, which was submitted to the Parliament in 1918 and approved in 1937, already included the current Article 115, entitled "inducement and assistance to commit suicide", which reads: "Every person who, for selfish reasons, incites or assists someone to commit suicide, shall be sentenced to imprisonment of up to five years or a fine."

This article is interpreted a contrario as meaning that assistance with suicide is not a criminal offense when it is practiced without any self-interested motivation. There would be a selfish motivation if, for instance, the assisting person would inherit the one who is seeking to die, or would benefit in some other way from the death of the latter. But because nonprofit organizations do not have, in principle, any selfish motivations for helping someone to commit suicide, their activities are not illegal.

Certainly, Article 115 of the Penal Code was not originally conceived with the purpose of "legalizing" assisted suicide, let alone facilitating the activities of nongovernmental organizations involved in this practice. Rather, the authors of the draft Penal Code had in mind the situation of somebody who assists a desperate individual wanting to end his or her life for some personal reasons; the lawmakers decided to exclude imprisonment when the assisting individual acted without any personal interest. The whole parliamentary discussion in the 1930 s did not envisage at all suicide assistance from a medical perspective. It was, rather, inspired by "romantic stories about people committing suicide in defence of their own, or their family's honour, and about suicides committed by rejected lovers". ${ }^{5}$

The unintentional character of the current permissive regime regarding assisted suicide explains the two aforementioned gaps in the Penal Code when compared with the provisions of other countries allowing this practice. First, it does not make any mention of physicians in the practice of assisted suicide. Second, no particular medical condition is required to request assistance with suicide.

Therefore, in Switzerland, anyone can in principle assist an individual to commit suicide, and any competent person can request such assistance. However, as mentioned previously, assisted suicide is in fact performed by volunteers working for nongovernmental organizations, and not by physicians. Interestingly, according to a study conducted in 2009, $80.4 \%$ of Swiss doctors are reluctant to be directly involved in this practice, which they consider to be a "nonmedical intervention" (although the majority of them do not regard the practice itself as morally reprehen sible). ${ }^{6}$

In addition, the Swiss Academy of Medical Sciences issued in 2004 guidelines on this matter expressing serious reservations about the involvement of physicians in assisted suicide. Paragraph 4.1 of the guidelines specifies that "the proper task of doctors is to relieve patients' suffering, not to offer them assistance to commit suicide."7 The rationale of this statement is that doctors' involvement in their patients' suicide risks creating confusion about the proper aim of the medical profession, on the side not only of the patients, but also of doctors themselves. It should be noted that these guidelines have been incorporated into the Professional Code of the Swiss Medical Association (Federatio Medicorum Helveticorum, FMH) and, in this way, they are binding for all practitioners.

However, the Academy itself nuanced the statement made in Paragraph 4.1. while acknowledging, in the same paragraph, that if a doctor, in accordance with his conscience, decides to assist in a suicide, his decision has to be respected: 
"On the one hand assisted suicide is not part of a doctor's task, because this contradicts the aims of medicine. On the other hand, consideration of the patient's wishes is fundamental for the doctorpatient relationship. This dilemma requires a personal decision of conscience on the part of the doctor. The decision to provide assistance in suicide must be respected as such.

In any case, the doctor has the right to refuse help in committing suicide. If he decides to assist a person to commit suicide, it is his responsibility to check the following preconditions: the patient's disease justifies the assumption that he is approaching the end of life; alternative possibilities for providing assistance have been discussed and, if desired, have been implemented; the patient is capable of making the decision, his wish has been well thought out, without external pressure, and he persists in this wish. This has been checked by a third person, who is not necessarily a doctor. The final action in the process leading to death must always be taken by the patient himself."

\section{The Role of Nongovernmental Organizations in Assisted Suicide}

The debate on assisted suicide in Switzerland has essentially to do with the role of nonprofit organizations offering that assistance, and not with the involvement of physicians or with particular medical conditions for such a request. There are two main nongovernmental organizations involved in this practice: Exit and Dignitas. They usually perform the suicides in their own accommodations. Sometimes they rent apartments for this purpose. Suicides do not take place in public hospitals, except in Geneva and Lausanne, which have authorized them. However, even in these cases, assistance to suicide is not performed by the physicians themselves, but by the volunteers working for the organizations.

Exit, which was created in 1982, offers its services only to residents in Switzerland. According to the internal regulations of the association, people seeking help to commit suicide must be legally competent, exhibit a constant and consistent desire to die, and be experiencing "unbearable suffering, or be disabled in a serious manner." Exit workers follow a protocol and use a checklist to document what was discussed at the initial visit and all subsequent contacts. Most members who are considered eligible for assistance are close to death, and Exit routinely recommends both hospice care and notification to the family. The association has two branches: Exit Deutsche Schweiz, which operates in the German-speaking part of Switzerland, with headquarters in Zurich, and Exit ADMD (Association pour le Droit de Mourir dans la Dignité) for the Frenchspeaking part of the country, with headquarters in Geneva. They have 55,000 and 10,000 members respectively. ${ }^{8}$

Dignitas was created in 1998 by the lawyer Ludwig Minelli and offers assisted suicide to nonresidents in Switzerland. It has at present 5.500 members. ${ }^{9}$ People seeking to end their lives have to register with the society, pay a registration fee (200 Swiss Francs: around 160 Euros), and an annual fee of 80 Swiss Francs, and when (and if) they decide to kill themselves, they have to pay a total amount of 6,000 Francs (around 5,000 Euros), which includes the administrative and burial costs. Members also have to give a power of attorney to the society for all the administrative procedures. Most people seeking assistance to suicide come from Germany, the UK, and France. More than 100 Britons have been assisted to die by this organization. This particularity has generated a heated debate in Switzerland about the so-called death tourism.

Media scandals occur regularly about the suicide tourism that results from the activities of Dignitas, and about the contentious ways in which assisted suicide has been practiced in some cases (in a car at a parking lot and using a plastic bag, or by breathing helium gas, etc.). ${ }^{10}$ Former volunteers of the organization have in the past claimed that it is doing business with death, and that it does not give people enough time to reconsider their wish to die. ${ }^{11}$ There 
have been reports indicating that people have received the lethal drug the same day on which they arrived to Switzerland, and after only a short interview. Dignitas is also regularly accused of not being transparent enough regarding its financial practice. It is also suspected of receiving legacies from the people seeking to commit suicide. This practice, if confirmed, would put into doubts the altruistic nature of the assistance and its conformity with Article 115 of the Penal Code.

Although physicians are not directly involved in suicide assistance, this does not mean that they do not play any role in this practice: everyone seeking to commit suicide must be examined by a doctor, who, according to the Swiss Law on Pharmaceutical Products (2000), is the only who can prescribe the lethal drug used for that purpose (sodium pentobarbital). This drug is a narcotic, but when it is administered at a high dose (15 grams), it has a lethal effect. If a doctor refuses to prescribe the drug to the patient, the organization can refer the individual to a collaborating physician who will consider assessing the patient's capacity and eventually prescribe the drug. In practice, usually the doctors who prescribe the lethal drug are working closely to the organization.

The Law on Pharmaceutical Products provides that "the prescribing and dispensing of pharmaceutical products must be carried out in accordance with the recognized rules of medical and pharmaceutical practice" (Article 26.1). This raises a matter of interpretation as to whether prescribing a lethal drug to a person seeking to commit suicide is in conformity with medical practice. The courts have held that, in principle, this legal provision is not in conflict with assisted suicide, but that the doctor must examine the patients' wishes to die, and assess their competence to make such a decision. ${ }^{12}$

So far none of the assisted suicide organizations or one of their directors have been convicted under Article 115 of the Penal Code. However, the Federal Court has had occasion to point out that a condemnation would be possible if the assisting person has not examined with sufficient care if the individual seeking suicide was mentally competent. On this ground, in 2009, the court convicted a psychiatrist for homicide by recklessness for having assisted the suicide of two persons suffering from mental illness. ${ }^{13}$

Three years before that judgment, on November 3, 2006, the Federal Court had admitted that an incurable and serious mental disorder may also justify the recourse to assisted suicide, but in this case a report by a psychiatrist should provide evidence that the patient's wish to die is not the expression of the psychiatric disorder itself. This decision was severely criticized by the Swiss Federation of Medical Doctors on the grounds that it is dangerous to allow assisted suicide for psychiatric patients, because it is extremely difficult, if not impossible, to determine whether or not the wish to die is the result of the psychiatric disorder. ${ }^{14}$

Another conflicting issue is whether healthy individuals can also be assisted to commit suicide. As aforementioned, the Penal Code does not explicitly exclude this possibility. This debate was reignited in July 2009, as the former conductor of the BBC Philharmonic Orchestra, Sir Edward Downes chose to die alongside his wife at the Dignitas clinic in Zurich. His wife had been suffering from terminal cancer, but he was not terminally ill. He was 85 year old, and almost blind, but not terminally ill. ${ }^{15}$ This was not the first time Dignitas has assisted with double suicides in which one person was not terminally ill.

The Federal Court has also had the opportunity to clarify issues relating to the prescription and storage of the lethal drug used to commit suicide, and to the withdrawal of the permission to practice medicine. In 2010 the court concluded that the requirement that one must have a medical prescription to obtain sodium pentobarbital is not contrary to the right to privacy. ${ }^{16}$ The European Court of Human Rights confirmed this judgment, rejecting the allegations of the applicant according to which the State would have 
a positive obligation to facilitate suicide. According to the Court, the state must ensure the protection of life, in conformity with Article 2 of the Convention (right to life). Even when assisted suicide is allowed, as it is the case in Switzerland, the state must prevent abuse in the use of this faculty because of its obligation to protect life. ${ }^{17}$

In 2008, the Federal Court confirmed the decision of the Department of Health of the Canton of Zurich, which refused to grant a renewal of the license to practice medicine to a 70 -year old doctor who had prescribed sodium pentobarbital to elderly patients after just a single interview. ${ }^{18}$

One year later, the Federal Court determined that, according to Article 14a of the Law on Drugs and Psychotropic Substances, Dignitas was not authorized to store sodium pentobarbital in its accommodations or to provide it directly to the individuals seeking to commit suicide. ${ }^{19}$

\section{A Failed Attempt to Regulate Assisted Suicide}

Throughout the last decade the Swiss authorities have tried to establish some minimal rules relating to assisted suicide, but without success. ${ }^{20}$ In 2009 , an agreement signed between the Canton of Zurich and Exit in order to regulate this practice within the canton raised a serious controversy and was one year later invalidated by the Federal Court. The debate was about the proper role of the state in this matter. Some argued that public authorities have nothing to negotiate with nongovernmental organizations regarding the way in which assisted suicide is practiced because this is an issue of public interest that only the state (preferably the Federal State, not each canton) can regulate.

The agreement included very detailed rules and, in general, endorsed the current practice. It provided, for instance, that the only method allowed is sodium pentobarbital; that the volunteers cannot receive more than 500 Swiss francs (approximately 420 euros) for each person they assist. The required medical condition was very broad conceived: it was defined as a "serious suffering due to a disease", but not necessarily a terminal disease.

Pro-life societies brought the case before the Federal Court, arguing that the agreement was contrary to the Constitution. The agreement was invalidated on 16 June 2010 by the Federal Court, which came to the conclusion that such an agreement between individuals and public authorities is illegal, as it entails an undue extension of Article 115 of the Penal Code relating to assistance with suicide. In addition, the right to life, which is at the center of the agreement, is of such great importance that only the federal legislature is competent to regulate such issues.

Simultaneously, the Federal Council (the executive body) presented in October 2009 two different draft bills for consultation to the Swiss parliament. Basically, the government did not wish to take anything away from the current, liberal legal situation. However, because assisted suicide organizations are increasingly testing the boundaries of the law, and in some cases evading state and professional monitoring mechanisms, the Federal Council considered an urgent need to lay down minimal rules, which should ensure that assisted suicide is only available to terminally ill patients, and not to those with a chronic or a mental disease. These rules should also prevent organized assisted suicide becoming a profit-driven business. The government also expressed its willingness to promote palliative care and suicide prevention to offer suicidal individuals alternatives to taking their own life. As a result of this initiative, two options were elaborated:

Option 1: Regulation of the Practice of Organized Assisted Suicide

According to one of the bills, which was preferred by the majority of the members of the Federal Council, Article 115 should be amended to include a 
number of duties of care. The following elements are significant in this regard:

1) Free will and time of reflection: the person seeking to commit suicide must freely declare their wish to die, and must have given long and proper consideration to their decision. This provision was intended to prevent impetuous decisions that have not been thought through;

2) Two doctor's certificates required: the person who wishes to die must present two certificates from two different doctors who are independent of the assisted suicide organization. One of the certificates must attest that the suicidal person has the legal capacity to decide for him- or herself; the second must state that the suicidal person suffers from a physical illness that is incurable and will result in death within a short period. This would rule out organized assisted suicide for those with chronic illnesses that are not in themselves terminal, and for those suffering mental illness. Comprehensive treatment, care and support -in the sense of palliative medicine- should allow these people to continue to live in dignity.

3) Non-commercial purpose: those assisting in a suicide must discuss and examine alternatives to suicide with the person concerned. The drug that is used must have been prescribed by a doctor. This demands that a diagnosis and the corresponding indications be established in accordance with the physician's professional obligations and duties of care. Those assisting in a suicide may not be pursuing commercial ends. They may not accept any payment for their services that would exceed the costs and expenses of the assisted suicide. This provision ensures that those assisting in a suicide are not driven by personal gain, and that their prime motivation is to help the person who wishes to die. Finally, the assisted suicide organization and those who actually assist with the suicide must document each case comprehensively in order to help any enquiries on the part of the criminal prosecution authorities.

\section{Option 2: Total ban on organized assisted suicide}

The second option, proposed by Pascal Couchepin (member of the Federal Council at that time), consisted in a complete ban on organized assisted suicide. This option rested on the conviction that suicide should remain an individual issue, and should not in any way be supported by the state. According to its author, it is contradictory for the state, on the one hand, to promote respect for life as well as to prevent suicides, and, on the other hand, to regulate how the practice of suicide should be organized. In addition, it is dubious that people working for assisted suicide organizations are motivated by purely altruistic reasons, because they are paid for that assistance.

Both options generated considerable controversy within the consultation procedure. If the majority of participants agreed that it was necessary to legislate at the federal level, no clear consensus on the solution to this sensitive issue was reached. Many participants in the consultation procedure seized the opportunity to demand the implementation of measures to prevent suicide and promote palliative care.

In September 2010, the government instructed the Department of Justice to prepare a draft amendment of Article 115 of the Penal Code along the lines of option 1 , and to take into account the criticisms addressed to it during the consultation procedure. Meanwhile, the Council instructed the Department of Home Affairs to propose measures to 
strengthen palliative care and suicide prevention.

In June 2011, both departments arrived to the conclusion that an amendment to Article 115 of the Penal Code would not improve the current situation, and would carry many disadvantages, such as the legitimization of assisted suicide organizations, the relativization of the value of human life, and the likely resistance of the medical community to the implementation of the new rules. They concluded that the abuses taking place in the practice of assisted suicide (for instance, suicide for incompetent persons and for persons in good health, provision of the lethal drug without prescription, unlawful storage of the drug, etc.) can be fought using the legal tools that are currently available. In July 2011, the government, following the recommendation made by both departments, decided not to propose any specific legal norm relating to assisted suicide and to adopt measures to prevent suicides and to promote palliative care in order to reduce the number of suicides.

\section{Conclusion}

Switzerland is the only country in Europe that allows nonphysician assisted suicide, and that does not require any particular medical condition for receiving such assistance. Nonprofit organizations play a central role in this practice as their volunteers are those who directly assist people seeking to commit suicide, whereas doctors prescribe the lethal and assess the patient's decisional capacity, but do not assist directly patients in the suicide.

The current situation is not the outcome of a deliberate liberal policy, but is the unintended result of a gap in the Swiss Penal Code, which does not punish assisted suicide when the assisting person is without selfish motivations. In 2009, the government tried to fill this gap by examining the opportunity of introducing specific legislation to regulate this matter. However, in June 2011, after careful consideration, it came to the conclusion that specific legal regulation on assisted suicide would not improve the current situation and would carry many disadvantages. On these grounds, the government decided to focus on the adoption of measures to strengthen palliative care and suicide prevention.

\footnotetext{
Notes

${ }^{1}$ Guillod O. and Schmidt, A. Assisted suicide under Swiss law. European Journal of Health Law 2005, 12(1): 25-38, at 26.

${ }^{2}$ Bosshard G. Switzerland. In: J. Griffiths and H. Weyers (eds.). Euthanasia and Law in Europe, Oxford: Hart Publishing, 2008, 463-481

3 Ziegler S and Bossard, G. Role of nongovernmental organizations in physician assisted suicide. British Medical Journal 2007; 334:295298.

${ }^{4}$ Fischer S. Huber C.A. Imhof, L. Mahrer Imhof R. Furter M. Ziegler S.J., and Bosshard G. Suicide assisted by two Swiss right-to-die organisations. Journal of Medical Ethics 2008;34(11):810-814.
}

${ }^{5}$ See note 1, Guillod and Schmidt 2005:29; Hurst S. and Mauron A. Assisted suicide and euthanasia in Switzerland: allowing a role for non-physicians. British Medical Journal 2003;326:271-273.

${ }^{6}$ Pfister, E. and Biller-Andorno N. The reception and implementation of ethical guidelines of the Swiss Academy of Medical Sciences in medical and nursing practice. Swiss Medical Weekly 2010;140: 160-167. Available at: http://www.smw.ch/docs/PdfContent/smw12647.pdf

${ }^{7}$ Swiss Academy of Medical Sciences, Guidelines. Care of patients in the end of life. 2004. At: http://www.samw.ch/en/Ethics/Guidelines/Currentl $\mathrm{y}$-valid-guidelines.html

${ }^{8}$ See Exit website: http://www.exit.ch

${ }^{9}$ See Dignitas website: http://www.dignitas.ch

${ }^{10}$ Ledig M, Samuel H. Swiss suicide groups operates in car parks. The Telegraph, 9 November 2007; Konnolly K. Dignitas attacked for new assisted-suicide method, The Guardian, 21 March 2008; Euthanasia group Dignitas films gas and plastic bag deaths, Daily Mail, 19 March 2008.

${ }^{11}$ Hall A. Cashing in on despair ? Suicide clinic Dignitas is a profit obsessed killing machine, claims ex-worker. The Mail, 25 January 2009.

${ }_{12}$ Zurich Administrative Court, 3rd Chamber, 15 July 1999.

${ }^{13}$ Federal Court, 11 June 2009, Decision 6B_48/2009.

${ }^{14}$ Ragenbass R. and Kuhn H. L'aide au suicide n'est pas un droit humain. Bulletin des médecins suisses 2007;88(11):455-456.

${ }^{15}$ British conductor dies with wife at assisted suicide clinic. The Guardian, 14 July 2009. Available at: 
http://www.guardian.co.uk/society/2009/jul/14/assi sted-suicide-conductor-edward-downes

16 Federal Court, 12 April 2010. Decision 2C_9/2010.

${ }^{17}$ European Court of Human Rights, Haas v. Switzerland, 20 January 2011. Application $\mathrm{N}^{\circ}$ 31322/07.

18 Federal Court, 24 June 2008. Decision 2C_191/2008.

${ }^{19}$ Federal Court, 1 April 2009. Decision 2C_839/2008.

${ }^{20}$ Dryer C. Swiss parliament may try to ban 'suicide tourism'. British Medical Journal 2003; 326:242. 